\title{
La oración comunitaria .
}

Todos los autores, que se interesan por el tema de la oración, coinciden en afirmar que la oración es elemento indispensable para una adecuada renovación de la vida religiosa. Sirvan de ejemplo algunos testimonios. «El medio privilegiado, por su eficacia, para asegurar la permanencia y el fortalecimiento de la vivencia religiosa es, sin duda, la oración. No entro a discutir aquí las razones a favor o en contra de la oración. Es una cuestión de fe. Quien cree en Dios, tal como se revela en la Biblia, percibe enseguida que existe un diálogo entre Dios y el hombre. Y quien dice diálogo dice relación. Dios habla al hombre y espera que éste le responda. La oración es la historia del ilimitado y absolutamente gratuito amor de Dios al hombre, el cual se siente irresistiblemente solicitado a responder con su pobre amor humano» ${ }^{2}$.

«Es algo incuestionable que en la vida espiritual no todas las cosas reclaman la misma atención ni merecen el mismo esfuerzo; ni todos los defectos entorpecen en el mismo grado, ni todas las virtudes tienen la misma excelencia, ni todos los métodos la misma eficacia, ni son necesarias todas las devociones.

Todo esto lo debe saber la persona y todo esto lo debe tener en cuenta, sobre todo, el que guía, para no malograr esfuerzos y sembrar desilusiones.

Se ha de tender, por lo mismo, desde el principio, an objeto único, teniendo en cuenta la limitación de la persona y la desigual eficacia santificadora de los resortes a nuestra disposición; procurar averiguar cuál es el resorte de verdad central, que dé eficacia y consistencia a todo el mecanismo, para hacer confluir en él la atención más perseverante y los esfuerzos mejores de la persona, aunque parezca que todo lo demás queda un poco en la penumbra; que será sólo en apariencia...

1. Este capítulo es un apartado de un escrito dedicado a la Iglesia-ecucaristía-comunidad.

2. Finkler, P., Cuando el hombre ora. Ed. Paulinas, Madrid 1981, 22. 
¿Y cuál será el resorte clave dotado de esta eficacia maravillosa? Creo que no es menester cansarse mucho en averiguarlo. Es la vida de oración. $\mathrm{Pa}$ rece que no puede caber duda» ${ }^{3}$.

«Decididamente, si el testimonio de los cristianos no es también testimonio de oración, poco o mejor nada tienen que decir en este mundo... Ofrecer en este tiempo una alternativa real, es decir con hechos, que lo importante no está en tener, sino en ser» ${ }^{4}$. Es importante resaltar que este último texto está referido al cristiano sin más. ¿Qué se deberá afirmar del religioso o. de la religiosa?

Los textos citados, todos ellos de autores de nuestro tiempo, con posibilidad, por tanto, de conectar con los problemas más relevantes de nuestro mundo, ponen a las claras la importancia trascendental de la oración en la vida cristiana y, como derivación absolutamente legítima, en la vida religiosa. Ello puede conducir a la convicción de que ello es suficiente y excluir por lo mismo cualquier duda al respecto. Con todo el tema de la oración es un tema con muchas aristas. Puede conducir a un sentimentalismo exacerbado, traducido, en ocasiones, en una praxis incoherente con la propia condición humana. Puede también fomentar un indiferentismo de tales quilates que lleve como de la mano al abandono de la oración propiamente dicha. Entre ambos extremos se pueden situar posturas más o menos correctas o incorrectas.

Con el fin de superar uno $u$ otro inconveniente, se impone la tarea de hacer un breve recorrido por las páginas de la revelación y por los escritos de aquellos autores que, por su carisma especial, pueden hablarnos de la oración con autoridad convincente. En un tema como éste poco valen las convicciones personales. Es preciso dejarnos guiar tanto por el mensaje de la revelación, como por el testimonio de quienes han sabido andar por los caminos de la perfección cristiana. El recorrido, como fácilmente se puede adivinar, será esencialmente corto, aunque suficientemente significativo.

Está fuera de duda que Jesús, modelo y maestro del cristiano, fue un hombre de oración. Los testimonios evangélicos al respecto son elocuentes. (Cf. Mt 4,1-11; 11,25-27; 26,36-44; Mc 1,35; Lc 3,21-22; 5,16; 6,12-15; 9,18; 9,28-29; 10,38-42. Jn 11,41-42; 12,27-28; 17,1-26.

Jesús, en verdad, ora y ora con la conciencia de que se trata de algo esencial en su vida y en el cumplimiento de su misión. Fruto de esta experiencia vital, Jesús recomienda la oración y ofrece una doctrina maravillosa sobre la misma (Cf. Mt 6,5-13; 7,7-11; 18,19-20; 26,41. Mc 11,20-25. Lc 11,5-13;

3. Juberías, F., Buscaré, Señor, tu rostro. Instituto teológico de la vida religiosa. Madrid $1982,22-23$.

4. CAStillo, J.M., La alternativa cristiana. Sígueme, Salamanca 1971, 225. 
18,1-4. Jn 14,13-14; 14,15). La síntesis de todo el mensaje de Jesús sobre la oración se halla en esta hermosa frase recordada por Lucas: «es necesario orar siempre y no desfallecer» $(18,1)$.

Pablo es el gran teólogo del misterio cristiano. Su identificación con Cristo es tan extraordinaria que Juan Crisóstomo ha podido afirmar que el corazón de Pablo es el corazón de Cristo. Pocos hombres han llegado a sentirse tan plenamente identificados con el Señor como lo ha estado Pablo. De ahí que resulta fácilmente comprensible que Pablo haya sintonizado con Cristo en un tema tan decisivo como es el tema de la oración. Primero, por su vida de oración. Segundo, por su mensaje sobre la oración. Pablo es un orante fuera de serie y, como consecuencia, ofrece sobre la oración unos textos expléndidos. Se pueden ver los textos siguientes: Rom 1,10; 12,12. Ef 6,18. Col 1,3.1; Tes 5,17. 2 Tes 1,11. El tono de su mensaje oracional llega a su máxima tensión en este pasaje: «Estad siempre gozosos y orad sin cesar. Dad en todo gracias a Dios, porque tal es su voluntad en Cristo Jesús respecto de vosotros» (1 Tes 5,17-18).

La epístola de Santiago, un escrito eminentemente práctico, ofrece un texto espléndido sobre la oración: «Mucho puede la oración fervorosa del justo. Elías hombre era, semejante a nosotros, y oró para que no lloviese, y no llovió sobre la tierra durante tres años y tres meses; de nuevo oró, y envió el cielo lluvia y produjo la tierra sus frutos» $(5,16 \mathrm{c}-18)$.

De los autores bíblicos pasamos a los autores ascético-místicos. La fuerza de sus palabras se basa en dos realidades: presentan, en primer lugar, una coherencia total con el dato bíblico y expresan, en segundo lugar, una experiencia personal del misterio de Dios. Comienzo citando a Casiano, el célebre monje que tanto ha influido en la espiritualidad de Occidente: "Ya veis, dice, que el Señor coloca el bien principal en la teoría, es decir, en la contemplación divina. De donde se sigue que las otras virtudes, por buenas y útiles que nos parezcan, deben, no obstante, ser relegadas a segundo término, supuesto que todas ellas se alcanzan por mediación de ésta. Por eso, al decir el Señor: -andas muy solícita y te turbas en muchas cosas, pero pocas son necesarias; o más bien una sola - sitúa el bien soberano no en la acción, por laudable y fecunda que parezca en los resultados, sino en la contemplación de Él mismo» ${ }^{5}$. $\mathrm{Y}$ en otro lugar afirma: «El fin del monje y la más alta perfección del corazón, tienden a establecer en una continua e ininterrumpida atmósfera de oración» ${ }^{6}$.

Catalina de Siena es una de las dos mujeres que ha recibido oficialmente

5. CASIANO, Colación primera, núm. VIII.

6. Casiano, Colación novena, II. 
el título de Doctora. Lo cual conlleva el reconocimiento del valor que tiene"para la Iglesia su mensaje doctrinal. Catalina de Siena afirma acerca del valor de la oración: «De ninguna manera gusta tanto a la criatura y es iluminada de aquella Verdad, cuanto por medio de la oración humilde y continua» ${ }^{7}$.

No pueden faltar a esta cita los dos grandes místicos españoles: Teresa de Jesús y Juan de la Cruz. Ellos han sido, sin duda, los mentores más grandes de la espiritualidad de Occidente. Teresa de Jesús dice sobre la oración: «Pues creedme vosotras y no os engañe nadie en mostraros otro camino sino el de la oración» ${ }^{8}$. Juan de la Cruz no es menos contudente. Afirma: "La oración mental ha de prevalecer sobre todo otro ejercicio: ella es la fuerza del alma» ${ }^{9}$.

Todos estos testimonios, tan elocuentes y claros, reciben su apoyo cualificado del magisterio actual de los Papas. «El magisterio de la Iglesia ha reconocido siempre la importancia decisiva y hasta la absoluta necesidad de la oración en toda forma de vida cristiana. Sin oración no es posible ser cristiano.

De una manera especial, en la vida sacerdotal y religiosa, la oración resulta no sólo necesaria, sino constitutiva esencialmente de ese estilo de vida cristiana» ${ }^{10}$.

«La fidelidad a la oración o el abandono de la misma son el paradigma del vigor o del ocaso de la vida religiosa» ${ }^{11}$.

«La oración diaria, hecha con fidelidad, sigue siendo para cada uno y para cada una de los religiosos y de las religiosas una necesidad primaria y, por lo mismo, debe ocupar el primer puesto en sus Constituciones y en su vida» ${ }^{12}$.

«Para conservar bien nítida la percepción del valor de la vida consagrada, se requiere una visión profunda de fe y ésta se sostiene y se alimenta mediante la oración... Sin la oración, la vida religiosa pierde su significado y no consigue su finalidad» ${ }^{13}$.

Aunque se trate de un número relativamente reducido, los textos citados son de tal calidad y contienen un mensaje tan directo y explícito que supondría una temeridad, al menos desde la fe, despojarlos de valor. Es evidente, en atención a lo dicho, que la oración constituye el pilar más firme de una auténtica espiritualidad y la fuente más abundosa de un apostolado fecundo. Y esto a todos los niveles del compromiso cristiano. Lo cual sube de tono, cuando se trata de una vida tan peculiar como es la vida religiosa. Una vida que, por sus

7. Santa Catalina de Siena, Diálogos, I cap. 1.

8. Santa Teresa de Jesús, Camino de perfección, 36,2.

9. SAN JuAN de la CRuz, Grados de perfección, 5.

10. Juberías, F., Buscaré, Señor, tu rostro, 26.

11. Pablo VI, ET. 42.

12. PABlo VI, Discurso, 20-8-1969.

13. Juan Pablo II, Discurso, 7-3-1980. 
mismas características, está llamada a traducirse en una intensa y profunda experiencia de Dios. Juan Pablo II recuerda a los.religiosos, y lo hace con un énfasis particular, que «sin la oración, la vida religiosa pierde su significado y no consigue su finalidad» ${ }^{14}$. Un autor moderno se expresa en la misma línea de pensamiento: «La vida de oración es el ejercicio más alto, más completo, más intenso y más constante de las tres virtudes teologales, pues, por el hecho de orar, se están ejercitando las tres virtudes teologales a un tiempo. Según sea la comunicación del cristiano con el seno del Padre a través de este conducto, que es la oración, así será la fuerza de la vida divina en él. Si es profunda y constante, la vida espiritual se desarrollará vigorosa. Si es poco profunda y poco frecuente, se desarrollará lánguida y amenazará constantemente la anemia espiritual. Si este conducto se obstruye o se corta, morirá en él la vida divina a muy corto plazo» ${ }^{15}$.

Me he referido a la oración sin más. Toca ahora tratar de una forma muy concreta de la misma. Voy a hablar de la oración comunitaria. Hay que recordar que estas reflexiones están motivadas fundamentalmente por el tema de la comunidad. Comunidad que no nace por generación espontánea, sino que es preciso construir. Y que lleva, por tanto, unas exigencias prácticas, que hay que llenar. Entre tales exigencias se encuentra con carácter prioritario la oración comunitaria. Es ésta la oración de la comunicación por antonomasia. Y, por tanto, medio insustituible en la construcción de la comunidad, que, como es fácilmente inteligible, tal labor se lleva a cabo principalmente por la comunicación. Comunicación a todos los niveles. Por tanto, también a nivel ci. ración, de experiencia de Dios.

El tema, que estoy tratando es de tal envergadura para la comunidad agustiniana, que ello impone dedicarle máxima atención. Valga, de entrada, esta frase del Documento de Dublín: «El capítulo está convencido de que, si nosotros, agustinos, no conseguimos una renovación de la vida en común, a la luz del nuevo testamento y del espíritu de san Agustín, el resto de nuestros problemas (crisis de vocaciones, crisis de identidad, problemas apostólicos, etc.) no se resolverán ni surgirá una vitalidad en la orden» ${ }^{16}$.

Tras este párrafo, denso y serio, grandemente serio, el documento de Dublín presenta el diseño de lo que debe ser una comunidad agustiniana. «Nuestra vida común sólo tendrá fuerza en medio del mundo, si la vivimos con la intensidad querida por san Agustín. El modelo por él elegido es la primitiva comunidad de Jerusalén, que cultivaba explícitamente la comunión (koinonía).

14. JUAN PABLo II, Ib.

15. JUBERÍAs, F., Buscaré, Señor, tu rostro, 28.

16. Documento de Dublín, Revista «Religión y cultura», julio-octubre 1974, 408. 
Esta comunión es una realidad distinta, más allá de las relaciones pacíficas. La crea una puesta en común constante no sólo de nuestros bienes materiales, sino también de nuestra intimidad psicológica y espiritual. Esta intercomunión, fundada en la presencia de Cristo en el hermano, desemboca en el gozo de la amistad; superando las distintas edades e ideologías. Además no sólo es una gozosa consecuencia de nuestra vida en común, sino también fuente de regeneración de la comunidad más genuina» ${ }^{17}$.

Este diseño de la comunidad agustiniana debe ir acompañado por una praxis concreta. Lleva consigo unas exigencias, que no pueden saltarse, si se quiere ser serios en los compromisos y si no se quiere dejar en la cuneta la empresa de construir la comunidad agustiniana. Una de esas exigencias, desde luego de una importancia trascendental, está marcada por la oración comunitaria. Por ser así, el citado Documento habla de ella en términos insuperables: «La comunidad agustiniana es como una iglesia pequeña, un grupo de personas que viven su fe. Nuestra oración es no sólo un acto de piedad, sino un estilo de vida. El diálogo con Dios es la cumbre del diálogo con nuestros hermanos. Por ellos y con ellos llegaremos al encuentro con el Señor. Y, para que esta fe madure, se necesita vivir no sólo la oración en común, sino también la oración participada o comunitaria, en la que haremos nuestras las experiencias personales de la unión con Dios de nuestros hermanos» ${ }^{18}$.

El texto es tan rico en contenido que se impone volver sobre él, para que nada se escape a la observación $y$, de este modo, pueda quedar marginado de la praxis. Y, con ello, privado de sus anhelados frutos. Se habla de la oración como estilo de vida. Hay aquí algo muy importante. Decisivo. Con frecuencia se ha tomado, y desgraciadamente se sigue tomando, la oración como un ejercicio de piedad. Un ejercicio de piedad que además se solía recluir en el espacio sagrado: iglesia o capilla. Ejercicio de piedad que no pocas veces carecía de influencia en la vida. Oración y vida marchaban con frecuencia de forma paralela. Desconociéndose. Ello supone un error de base gordísimo. La separación de oración y vida, que nunca se deben separar, y el consiguiente desprestigio de la oración, al carecer de efectos posibles.

Tal grave inconveniente sólo es superable viviendo la oración como estilo de vida. Y esto es lo que nos recuerda el Documento de Dublín. Oración y vida son, $\mathrm{y}$ así hay que vivirlas, dos caras de una misma moneda. Inseparables e interinfluyentes. La oración debe hacerse vida y la vida oración. El encuentro con Dios en la oración debe encontrar eco profundo en el encuentro con el hombre y la vida. El encuentro con el hombre y la vida deben surtir a la ora-

17. Documento de Dublín, Ib., 408-409.

18. Documento de Dublín, Ib., 409. 
ción de sus contenidos más densos, sólo así se traza el camino que puede culminar en una densa y profunda relación entre oración y vida. Y sólo así se evita que la oración quede reducida a una simple ideología.

Para evitar interpretaciones torcidas, se precisa hacer aquí algunas observaciones. Lo anteriormente dicho no puede ni debe considerarse como un desprecio o una marginación de los tiempos fuertes de oración. Tales tiempos son absolutamente necesarios. Y no pueden quedar velados por ningún sistema 0 fraseología basados en el sofisma. Es verdad que toda la vida tiene que ser oración. Es la meta a conseguir. Pero tal empresa resulta ilusoria, si se prescinde de los tiempos fuertes de oración. Estos tiempos deben distinguirse por su intensidad y extensión. Un ejemplo, aunque siempre con resultados limitados, puede hacernos comprender y valorar lo que se está diciendo. El organismo humano se está alimentando constantemente en una relación profunda con el entorno, en que se mueve. A pesar de eso, hay tiempos concretos en los que esa alimentación se hace de forma especial. Sin esta alimentación especial, suficiente y adecuada, el organismo humano va decayendo y puede incluso terminar en la muerte. Así acontece, salvadas las diferencias, en el campo de la vida espiritual. Quien descuida los momentos fuertes de oración, so pretexto de que toda la vida es oración, termina por sufrir quiebras importantes en su vida espiritual. Puede llegar incluso a la muerte.

«El diálogo con Dios es la cumbre del diálogo con nuestros hermanos. Por ellos y con ellos llegaremos al encuentro con el Señor». Son palabras del párrafo anteriormente citado. Palabras hermosas y cargadas de mensaje. $\mathrm{Pa}$ labras que piden algunas reflexiones, con el fin de alcanzar su máxima resonancia en nuestra mente y en nuestro corazón. Se nos dice, en primer lugar, que el diálogo con Dios es la cumbre del diálogo con los hermanos. Se usa en la frase el símil de la montaña. Una montaña consta de base y altura. Ambas se hallan unidas de tal forma que constituyen una unidad inseparable. La cumbre no está en el aire. Se apoya en la base. La base hace montaña, siempre y cuando esté coronada por la cumbre. Para alcanzar la cumbre, si nos atenemos al proceso normal, único válido en este caso, es necesario transitar antes por la base. Tal imagen nos facilita la comprensión de lo que acontece en el encuentro con Dios. El encuentro con Dios es la cumbre. Pero este encuentro se hace imposible, si, antes, no se pasa por el encuentro con los hermanos, que es la base. Sin el diálogo con los hermanos es imposible hablar de diálogo con Dios. O, dicho en otros términos, el diálogo con Dios resulta un engaño, cuando falta el diálogo con los hermanos.

Estamos, con seguridad, ante una afirmación un tanto sorprendente. Es normal, por tanto, que ello fuerce a hacer algunas preguntas: ¿Es así, de verdad? ¿No se estará cometiendo una exageración, dulce y bonita, pero, en de- 
finitiva, exageración? Así es y no se está cometiendo ninguna exageración. Para darse cuenta de la fuerza y del valor del tema, es preciso recordar aquí la relación profunda y vital que se da entre oración y vida, diálogo con Dios y diálogo con los hombres. Se trata de una relación necesaria y vital. Lo que quiere decir que la oración que se desgaja de la vida queda reducida a una simple, aunque bonita, ideología. La oración, pues, tiene que impulsar la vida y la vida tiene que alimentar la oración.

Dada esta profunda y fecunda interrelación, es preciso añadir que la oración, enmarcada en la vida, tiene un sujeto privilegiado. Es el hombre. Y, sobre todo, el hombre como hermano. Para el hombre de fe y, por tanto, para el orante, el hombre es imagen y semejanza de Dios. En el hombre Dios se refleja de manera especial. Todas las criaturas son, en verdad, reflejo de Dios. Pero el hombre es su espejo más límpido. Se da así una tarea primordial para el hombre. Es descubrir la imagen de Dios en el hombre-hermano. Quien alcanza a descubrir la presencia de Dios en el hombre-hermano da un paso de gigante en la ascensión de la cumbre que conduce al encuentro con Dios. El paso del encuentro con el hombre al encuentro con Dios resulta así fácil y suave. No hay estridencias bruscas. Por el contrario, quien no sabe descubrir a Dios en el hombre difícilmente, por no decir imposiblemente, puede ascender a la cumbre del encuentro con Dios. Nada hay, por tanto, que impulse mejor al encuentro con Dios que el verdadero encuentro con el hombre.

En todo este tema estoy haciendo uso de la palabra encuentro. Se trata de una palabra muy seria. Cargada de un contenido humano muy rico. Contenido que es necesario poner delante de los ojos. No se puede hablar de encuentro en cualquier relación humana. Las personas no se encuentran por el hecho de estar juntas. De relacionarse periféricamente. El encuentro, auténticamente humano, conlleva relaciones profundas. El hombre contacta con muchas personas, pero se encuentra con muy pocas. Ello nos habla de la calidad que debe alcanzar cualquier clase de encuentro y, sobre todo, el encuentro comunitario. Dicho encuentro, por tratarse de una comunidad religiosa, debe ser profundo, tocar las raíces más íntimas del ser humano y del ser religioso. Por ello, debe articularse, hilvanarse en fuerza al descubrimiento de la presencia viva del Señor. En él adquiere consistencia específica la comunidad religiosa. Los religiosos no se reúnen para hacer cosas, sino para vivir la presencia del Señor y gozar de ella. La profunda vivencia del encuentro con los hermanos coloca a los religiosos en el mejor de los caminos para alcanzar el y disfrutar del encuentro con Dios. No extraña que el Documento de Dublín pueda hablar con toda verdad del valor del encuentro comunitario para alcanzar el encuentro con Dios.

El encuentro con Dios y el encuentro con los hombres-hermanos tienen una manifestación bella y gratificante en la oración comunitaria. El Docu- 
mento de Dublín menciona con entusiasmo este modelo de oración. «Para que madure la fe, se necesita vivir no sólo la oración en común, sino también la oración participada o comunitaria, en la que hacemos nuestras las experiencias personales de la unión con Dios de nuestros hermanos» ${ }^{19}$.

Intentemos reflexionar sobre el contenido de la frase. Se habla de la maduración de la fe. Meta a la que debe tender todo creyente. La fe verdadera debe ser madura. Cualquier otra alternativa la empobrece. Sólo la madurez confiere a la fe la categoría de ser algo personal. Este carácter personal de la fe tiene hoy resonancias especiales. Antes, sin ser ello lo deseable, el entorno social favorecía una vivencia de la fe un tanto ambiental. Las defensas sociales hacían viable la existencia de una fe caracterizada por la tradición. Una tal fe era suficiente, aunque no fuera lo deseable, para impedir que hubiera destrozos sustanciales. Hoy esto es impensable. El ambiente es un ambiente de increencia. Es decir, un ambiente demoledor de una fe tradicional o basada en. factores ambientales. Es preciso, por tanto, conseguir que la fe adquiera un carácter personal. Que se viva como respuesta madura a la llamada de Dios, que sale al encuentro del hombre. La categoría encuentro define y califica a la fe. La fe es así encuentro con alguien más que recepción de algo. En este caso, encuentro personal entre Dios y el hombre.

El precio, que se debe pagar para alcanzar la madurez de la fe, es alto. Es precisamente la oración comunitaria. Éste es el mensaje que nos transmite el Documento de Dublín. ¡Ello significa que, si renunciamos a pagar el precio, renunciamos también a conseguir una fe madura, con todos los inconvenientes que ello lleva consigo. Seguro que a todos nos ilusiona acometer tal empresa. Todos queremos estar en posesión de una fe madura. Y, por ello, todos debemos optar por andar el camino de la oración comunitaria. Los beneficios son de tal categoría que bien merecen sacrificar lo que haya que sacrificar. Seguramente que viene aquí muy bien el recuerdo de la parábola de aquel que encontró un tesoro escondido. Lo vende todo para poder adquirir dicho tesorọ. La magnitud del tesoro compensa con creces todos los sacrificios que lleva el despojarse de muchas cosas amadas. La venta en este caso tiene un campo concreto. Y más que de venta hay que hablar de despojo.

La oración comunitaria, medio indispensable para llegar a la madurez de la fe; conlleva una serie de despojos. Es preciso despojarse del egoísmo. El egoísmo aísla, empobrece e impide poder llegar a ser hombres y creyentes perfectos. Es, sin duda, lo que más se opone a una fe adulta entendida como encuentro con Dios y con los hombres nuestros hermanos.

19. Documento de Dublín, Ib., 409. 
Es necesario despojarse de los miedos. El miedo amordaza e impide el uso de la palabra, medio por antonomasia de la comunicación. Sin el uso de la palabra es imposible lograr una comunicación adecuada, comunicación que hace posible la oración comunitaria.

Es necesario despojarse del afán de posesión. Nada de lo que el hombre tiene es sin más patrimonio suyo. Todo debe estar a disposición de los demás y debe ofrecerse sin miedos y con generosidad. De este modo la riqueza de cada cual ayuda a los demás y su pobreza queda superada con la riqueza de los demás. Si se tiene conciencia de que todo es don de Dios, ello nos debe empujar a ponerlo todo a disposición de los otros.

Hay que despojarse, por último, del frecuente complejo de inferioridad. Lo cual conlleva, como recompensa, saber aceptarnos en nuestra pequeñez. Todos podemos y debemos aportar algo a crear y aumentar la riqueza común. Cuando se trata de la oración comunitaria el aporte tiene una realidad concreta. Se trata de poner al servicio de los demás nuestra experiencia de Dios y de recibir de los demás sus experiencias de Dios. El dato no debe extrañar a nadie. Al contrario, debe verse con normalidad. La razón de nuestras comunidades es Dios. Todos los miembros estamos empeñados en una tarea común: hacer que tal presencià sea más viva en las comunidades. Hacer más sensible dicha presencia en nuestras vidas. Por tanto, todo lo que contribuya a conseguir tales realidades deberá saludarse con gozo y entusiasmo. $\mathrm{Y}$ debe intentarse sin escatimar sacrificios. Aquí está la fuerza y el valor de la oración comunitaria. Sin duda, el momento más adecuado para hacer realidad la aspiración de que Dios sea la razón de las comunidades.

Para tomar conciencia de que estamos ante algo esencialmente necesario para la vida religiosa, es conveniente volver a recordar que la comunidad religiosa es una iglesia en pequeño. Así es y así la presenta el Documento de Dublín. Tal hecho tiene unas consecuencias de primera magnitud. La primera y fundamental es que comunidad religiosa debe ser reflejo perfecto de lo que debe ser también la Iglesia de Cristo. De esta Iglesia se dice en forma enfática: «La Iglesia tiene que ser un grupo humano que tiene experiencia del Dios de Jesús, o deja de ser tal Iglesia. Por eso, una comunidad que no ora, que no celebra los sacramentos, que no expresa en su culto su relación trascendente y de fe, deja de ser la Iglesia de Dios y se constituye en una comunidad que ha perdido su carácter específico. Esto hay que defenderlo y subrayarlo ante las tendencias secularizantes e inmanentistas que se dan en la sociedad. La comunidad cristiana tiene que testimoniar que cree en Cristo y que se siente convocada por la experiencia de su Espíritu para vivir de acuerdo con el proyecto del reino... 
Por eso, lo más importante de la Iglesia es su experiencia de Dios» ${ }^{20}$.

Se nos dice que la Iglesia tiene que ser un grupo humano con experiencia del Dios de Jesús o deja de ser tal Iglesia. Esta experiencia es fundante y constitutiva para la Iglesia. Tales afirmaciones forman un mensaje de muchos quilates. Y la Iglesia debe reflexionar profundamente sobre él. Es mucho lo que se juega. Se juega su propio ser.

Si la comunidad religiosa, y en particular la comunidad agustiniana, es una iglesia en pequeño, entonces el mensaje anterior le afecta de lleno. Según ello, la comunidad religiosa debe ser, en pequeño, un grupo humano que se distinga por su experiencia de Dios. Tal experiencia es fundante y constitutiva para ella. Con lo cual está dicho todo lo que se puede decir, cuando se trata de algo vital.

Ello fuerza a plantearse algunos interrogantes: ¿Es así? ¿La experiencia de Dios es el elemento fundante y constitutivo de la comunidad religiosa agustiniana? ¿Se considera tal experiencia como la más importante para la comunidad? Por más que uno quiere ser optimista, la realidad impone su ley. Y es negativa. Las comunidades parecen estar a mucha distancia de una experiencia profunda de Dios. Y un dato indicativo de este lamentable fenómeno se halla en la ausencia de oración comunitaria. Tal estilo de oración no suele ser frecuente en la comunidad religioso-agustiniana. Y ello es indicio inequívoco de la falta de experiencia de Dios. La oración comunitaria tiene como finalidad comunicar a los demás nuestra experiencia de Dios y recibir de los otros su experiencia de Dios. Si tal experiencia existiera, no resultaría difícil comunicarla. Si esto no acontece, algo parece quedar fuera de duda: la ausencia o la no presencia activa de dicha experiencia. No se puede transmitir lo que no se posee o se posee deficientemente. De darse tal experiencia, la oración comunitaria sería la atmósfera por antonomasia para percibirla. De ahí que la ausencia de la oración comunitaria es una clara señal de que nuestras comunidades son más empresas de trabajo que comunidades reunidas en el nombre del Señor.

La ausencia, en mayor o menor grado, de la oración comunitaria es índice infalible de la falta de experiencia de Dios en los miembros de la comunidad. En ello está, desde luego, su daño más profundo, su mal más corrosivo. Pero no terminan aquí los males, los resultados negativos. El hecho afecta también al desarrollo humano de la persona. El hombre necesita, para su desarrollo integral, de la comunidad. y ello en virtud de la misma condición hu-

20. Estrada, J.A., Del misterio de la Iglesia al pueblo de Dios. Sígueme, Salamanca 1988, 194-195. 
mana. El hombre se dice, con toda verdad, es un ser en relación. Debe, por tanto, crecer armónicamente en la doble dirección que indica la frase: hacia adentro y hacia afuera, en sí y con los otros. Se dice que debe crecer armónicamente, para descalificar un crecimiento desmedido en una dirección y raquítico en otra. Con ello se indica la necesidad de no entorpecer ninguna de esas direcciones. La comunidad, por tanto, se presenta como elemento necesario para un crecimiento armónico. $Y$ esto se exige no en cualquier nivel, sino en el nivel más profundo de la comunidad religiosa, que es la experiencia de Dios. Sin la experiencia de Dios, como clima comunitario, el crecimiento de las personas no puede alcanzar su meta. Y, por la relación íntima entre experiencia de Dios y oración comunitaria, hay que afirmar que sin oración comunitaria resulta inviable la consecución del desarrollo íntegro de las personas religiosas.

El Documento de Dublín hace un balance amplio de las ventajas que conlleva la vida comunitaria vivida en la profundidad apuntada. Dice: «Entendida así la vida en común, es fácil hallar una respuesta a la antinomia personacomunidad, tan frecuente en todas las áreas de la sociedad humana. En este contexto de fraternidad mutua, la persona recibe más que da, y no solamente no queda ahogada por la comunidad, sino que está constantemente enriquecida por ella. Sabemos que el precio de la unidad, no pequeño por cierto, es morir al individualismo. Pero bien merece la pena pagarlo a cambio de la riqueza que dimana de la comunidad. Por otra parte, tanto el superior como los demás miembros deben estar atentos a las necesidades de cada individuo. Si deseamos tener comunidades de una calidad verdaderamente humana y religiosa, es imprescindible dar atención a la formación de hombres dè una personalidad madura y de una espiritualidad profunda» ${ }^{21}$.

Quiero ver en las últimas palabras un verdadero reto. Un reto que nos afecta a todos. «Si deseamos tener comunidades de una calidad verdaderamente humana y religiosa, es imprescindible dar atención a la formación de hombres de una personalidad madura y de una espiritualidad profunda». El Documento marca un precioso camino a seguir. Habla de una tarea insoslayable. Es necesario formar y esto hay que hacerlo fundamentalmente en el período de formación, hombres de personalidad madura y de espiritualidad profunda. Las comunidades no se hacen de la noche a la mañana. Hay que contar con los elementos adecuados. Y tales elementos deben fraguarse en las etapas de formación.

Es lógico que aquí no puedo entrar a desarrollar lo que conlleva una buena formación humano-religiosa. Teniendo en cuenta el tema, que me ocupa,

21. Documento de Dublín, Ib., 410-411. 
algo hay que decir sobre el particular. Durante el período de formación es necesario cultivar una profunda vida espiritual. Los jóvenes deben descubrir durante su período de formación la necesidad imperiosa que tienen de cultivar el diálogo intenso con el Señor. Y, a partir de ahí y nunca sin este presupuesto, deben acostumbrarse a llevar su experiencia de Dios a todos los demás hermanos por medio de la oración comunitaria. Cuando se siente a Dios como elemento aglutinante, que da sentido a la vida, las relaciones humanas de convivencia encuentran un amplio campo de realización. Es ahí en donde se aprende que la caridad es paciente y sabe soportar diferencias de carácter y de pensamiento. No se rechaza a nadie, porque en todos se descubre la presencia del Señor, razón suprema de la koinonía. Ẏ, al mismo tiempo, nadie se encierra en sí mismo, porque sabe, a través de su experiencia de Dios, que, como él vi-. no a dar la vida por los demás, también él debe darse sin medida a los otros.

Benito DoMínGUEZ 